\title{
Support for the predictions of the pollinator-mediated stabilizing selection hypothesis
}

\author{
Mark van Kleunen*, Anna Meier, Moritz Saxenhofer and \\ Markus Fischer \\ Institute of Plant Sciences, University of Bern, Altenbergrain 21, CH-3013 Bern, Switzerland \\ *Correspondence address: Institute of Plant Sciences, University of Bern, Altenbergrain 21, CH-3013 Bern, \\ Switzerland; Tel: +41-31-631-4923; Fax: +41-31-631-4942; E-mail: vkleunen@ips.unibe.ch
}

\begin{abstract}
Aims

Floral traits are frequently used in traditional plant systematics because of their assumed constancy. One potential reason for the apparent constancy of flower size is that effective pollen transfer between flowers depends on the accuracy of the physical fit between the flower and pollinator. Therefore, flowers are likely to be under stronger stabilizing selection for uniform size than vegetative plant parts. Moreover, as predicted by the pollinator-mediated stabilizing selection (PMSS) hypothesis, an accurate fit between flowers and their pollinators is likely to be more important for specialized pollination systems as found in many species with bilaterally symmetric (zygomorphic) flowers than for species with radially symmetric (actinomorphic) flowers.
\end{abstract}

\section{Methods}

In a comparative study of 15 zygomorphic and 13 actinomorphic species in Switzerland, we tested whether variation in flower size, among and within individuals, is smaller than variation in leaf size and whether variation in flower size is smaller in zygomorphic compared to actinomorphic species.

\section{Important findings}

Indeed, variation in leaf length was significantly larger than variation in flower length and width. Within-individual variation in flower and leaf sizes did not differ significantly between zygomorphic and actinomorphic species. In line with the predictions of the PMSS, among-individual variation in flower length and flower width was significantly smaller for zygomorphic species than for actinomorphic species, while the two groups did not differ in leaf length variation. This suggests that plants with zygomorphic flowers have undergone stronger selection for uniform flowers than plants with actinomorphic flowers. This supports that the relative uniformity of flowers compared to vegetative structures within species, as already observed in traditional plant systematics, is, at least in part, a consequence of the requirement for effective pollination.

Keywords: actinomorphy $\bullet$ flower size $\bullet$ floral

symmetry • phenotypic variance - zygomorphy

\section{INTRODUCTION}

The primary characteristics used in traditional plant systematics are floral traits (Grant 1949) because of their assumed constancy among individuals in a population. One potential reason for this constancy is that in animal-pollinated plants, effective pollen transfer between flowers depends on the accuracy of the physical fit between the flower and pollinator. Flowers that deviate strongly from the optimal size for accurate match with pollinators often produce fewer seeds (Nilsson 1988). This implies that flowers are likely to be under stabilizing selection for uniform size (Berg 1960). Optimum values of vegetative characteristics, such as leaf length, on the other hand, are likely to depend strongly on the local environment and might therefore be highly plastic (Bradshaw 1965). This implies that the amount of phenotypic variation within plant populations as shaped by evolutionary forces may strongly differ between floral and vegetative parts. So far, however, hardly any study has explicitly tested whether flowers are less variable than leaves (but see Armbruster et al. 1999).

An accurate physical fit between flowers and pollinators is particularly important in plant species with highly specialized pollination systems that are visited by only one or few species of pollinator and where pollen has to be deposited precisely on a definite part of the pollinator's body (e.g. Nilsson 1988). An important step enabling the evolution of specialized 
pollination systems has been the repeated evolutionary shift from radially symmetric flowers (i.e. actinomorphy) to bilaterally symmetric flowers (i.e. zygomorphy; Stebbins 1951, 1970). Zygomorphy is now found in c. $27 \%$ of the angiosperm families (Neal et al. 1998). Because zygomorphic flowers have, in contrast to actinomorphic flowers, only one plane of symmetry-reducing the number of possible positions of the pollinator on the flower-access to floral rewards and effective pollination allows for a higher degree of precision than in actinomorphic flowers (Berg 1960; Sargent 2004). This implies that floral size is likely to respond stronger to stabilizing selection in zygomorphic than in actinomorphic species. Wolfe and Krstolic (1999), therefore, hypothesized that variation in floral size should be smaller for zygomorphic species compared to actinomorphic species. Similar ideas had, however, been posited earlier with regard to plants with specialized and generalized pollination systems, irrespective of floral symmetry (Armbruster et al. 1999; Fenster 1991). The hypothesis of Wolfe and Krstolic (1999) has been referred to as the pollinatormediated stabilizing selection (PMSS) hypothesis (Ushimaru et al. 2007).

Whereas potential selective pressures by pollinators for reduced variation within flowers, measured as fluctuating asymmetry, have been frequently studied (e.g. Midgley and Johnson 1998; Møller and Eriksson 1994), the consequences of selective pressures on variation among flowers within populations have received much less attention. Wolfe and Krstolic (1999) tested their PMSS hypothesis for 31 species growing in southwestern Virginia, USA. In line with their prediction, they found that among-individual variation in floral size was lower for zygomorphic species than for actinomorphic species. Further support for the PMSS hypothesis was found in a study on 27 species in Japan (Ushimaru et al. 2007). To the best of our knowledge, no other studies have tested this hypothesis and as a consequence it is still difficult to draw conclusions on its general validity.

Phenotypic variation in flower size is not only determined by among-individual variation but also by within-individual variation. Whereas among-individual variation relates to genetic and environmental variation, within-individual variation relates to ontogenetic variation, developmental noise and microenvironmental variation. Stabilizing selection should, however, reduce both among-individual and withinindividual variations. So far, no study has tested whether the PMSS hypothesis applies to within-individual variation.

Therefore, we investigated flower size variation in a comparative study on 15 zygomorphic and 13 actinomorphic species growing in the vicinity of Bern, Switzerland. Moreover, because hardly any study has explicitly quantified differences in variation between flowers and vegetative structures, we also compared variation in flower size and leaf size. The specific questions that we addressed are (i) Is variation in floral size smaller than variation in leaf size? (ii) Is among-individual variation in floral size smaller in zygomorphic compared to actinomorphic species? (iii) Is within-individual variation in floral size smaller in zygomorphic compared to actinomorphic species?

\section{MATERIAL AND METHODS}

\section{Study species}

To test whether the size of flowers is less variable than the size of leaves and whether zygomorphic flowers are less variable in size than actinomorphic flowers, we measured sizes of flowers and leaves of 15 zygomorphic species and 13 actinomorphic species growing in the vicinity of Bern $\left(46^{\circ} 57^{\prime} \mathrm{N}, 7^{\circ} 26^{\prime} \mathrm{E}\right)$, Switzerland, during May to June 2007 (Table 1). For seven species (Dianthus carthusianorum, Fragaria vesca, Geranium pyrenaicum, Lamium purpureum, Lotus corniculatus, Medicago sativa and Salvia pratensis), we measured plants in two populations, and for the remaining 21 species, we measured plants in one population each. The only criteria for inclusion of a species in our study were that the species had at least 15 individuals in the study population and that the flowers were sufficiently large to be accurately measured with digital calipers.

\section{Measurements}

In each population of the 28 species, we measured the length and width of two randomly chosen flowers and the length of the two longest leaves on 15 randomly chosen individuals with digital calipers. For four species, Ranunculus repens, Papaver rhoeas, Geum urbanum and Fragaria vesca, we could measure only one flower per individual. For zygomorphic species, length of the flower was defined as the largest diameter in the vertical plane of the flower and width of the flower as the largest diameter in its horizontal plane. For actinomorphic flowers, the length of the flower was defined as its largest diameter and the width of the flower as its diameter perpendicular to its length.

\section{Analysis}

First, to test whether among-individual variation is larger than within-individual variation of species, we analyzed flower length, flower width and leaf length with analysis of variance. In this analysis, species, populations within species and individuals within populations were considered as random factors. To test whether values of among-individual variation in flower and leaf sizes differ between actinomorphic and zygomorphic species, we calculated for each individual the mean length and width of flowers and the mean length of leaves. From these individual mean values, we calculated for each population the among-individual coefficient of variation (CV; i.e. standard deviation divided by the population mean) of each of the three traits. To test whether values of within-individual variation in flower and leaf sizes differ between actinomorphic and zygomorphic species, we calculated for each individual with two measurements the within-individual coefficient of variation. From these individual CV values, we calculated for each 
Table 1: Taxonomic information and among-individual CV in flower length, flower width and leaf length among individuals for the 15 zygomorphic and 13 actinomorphic species used in this study

\begin{tabular}{|c|c|c|c|c|c|}
\hline \multirow[b]{2}{*}{ Species } & \multirow[b]{2}{*}{ Family } & \multirow[b]{2}{*}{ Subclass } & \multicolumn{3}{|c|}{ Among-individual CV } \\
\hline & & & Flower length & Flower width & Leaf length \\
\hline \multicolumn{6}{|l|}{ Zygomorphic } \\
\hline Echium vulgare L. & Boraginaceae & Asteridae & 0.090 & 0.113 & 0.202 \\
\hline Glechoma hederacea $\mathrm{L}$. & Lamiaceae & Asteridae & 0.099 & 0.093 & 0.256 \\
\hline Lamium purpureum L. & Lamiaceae & Asteridae & 0.050 & 0.070 & 0.249 \\
\hline Linaria vulgaris Mill. & Scrophulariaceae & Asteridae & 0.042 & 0.046 & 0.235 \\
\hline Lotus corniculatus L. & Fabaceac & Rosidac & 0.045 & 0.069 & 0.141 \\
\hline Medicago sativa $\mathrm{L}$. & Fabaceae & Rosidae & 0.097 & 0.102 & 0.182 \\
\hline Onobrychis viciifolia Scop. & Fabaceae & Rosidae & 0.064 & 0.083 & 0.212 \\
\hline Salvia pratensis $\mathrm{L}$. & Lamiaceae & Asteridae & 0.130 & 0.118 & 0.288 \\
\hline Securigera varia (L.) Lassen & Fabaceae & Rosidae & 0.030 & 0.067 & 0.141 \\
\hline Trifolium pratense $\mathrm{L}$. & Fabaceac & Rosidae & 0.049 & 0.080 & 0.142 \\
\hline Trifolium repens $\mathrm{L}$. & Fabaceae & Rosidae & 0.028 & 0.065 & 0.203 \\
\hline Veronica chamaedrys $\mathrm{L}$. & Scrophulariaceae & Asteridae & 0.069 & 0.059 & 0.287 \\
\hline Veronica persica Poir. & Scrophulariaceae & Asteridae & 0.080 & 0.095 & 0.240 \\
\hline Vicia cracca L. & Fabaceae & Rosidae & 0.039 & 0.143 & 0.166 \\
\hline Vicia sepium $\mathrm{L}$. & Fabaceae & Rosidae & 0.051 & 0.073 & 0.165 \\
\hline \multicolumn{6}{|l|}{ Actinomorphic } \\
\hline Alliaria petiolata (M. Bieb.) Cavara \& Grande & Brassicaceae & Dilleniidae & 0.115 & 0.122 & 0.299 \\
\hline Convolvulus arvensis $\mathrm{L}$. & Convolvulaceae & Asteridae & 0.155 & 0.142 & 0.264 \\
\hline Dianthus carthusianorum L. & Caryophyllaceae & Caryophyllidae & 0.089 & 0.090 & 0.221 \\
\hline Fragaria vesca $\mathrm{L}$. & Rosaceae & Rosidae & 0.079 & 0.091 & 0.294 \\
\hline Geranium pyrenaicum Burm. f. & Geraniaceac & Rosidae & 0.053 & 0.054 & 0.304 \\
\hline Geranium sylvaticum $\mathrm{L}$. & Geraniaceae & Rosidae & 0.111 & 0.124 & 0.135 \\
\hline Geum urbanum L. & Rosaceae & Rosidae & 0.126 & 0.124 & 0.244 \\
\hline Myosotis sylvatica Hoffm. & Boraginaceae & Asteridae & 0.071 & 0.075 & 0.127 \\
\hline Papaver rhoeas $\mathrm{L}$. & Papaveraceae & Magnoliidae & 0.229 & 0.262 & 0.336 \\
\hline Ranunculus acris $\mathrm{L}$. & Ranunculaceae & Magnoliidae & 0.129 & 0.133 & 0.526 \\
\hline Ranunculus repens $\mathrm{L}$. & Ranunculaceae & Magnoliidae & 0.102 & 0.097 & 0.195 \\
\hline Silene vulgaris (Moench) Garcke & Caryophyllaceae & Caryophyllidae & 0.116 & 0.124 & 0.180 \\
\hline Stellaria graminea L. & Caryophyllaceae & Caryophyllidae & 0.144 & 0.152 & 0.227 \\
\hline
\end{tabular}

population the average within-individual coefficient of variation. For the seven species in which we sampled two populations, we used the average CV over the two populations in the analyses.

Because CV values are generally not normally distributed, we used the non-parametric Wilcoxon rank-sum test for paired data to test whether among-individual CV of leaf length differs from the ones of flower length and width, respectively. We used the non-parametric Wilcoxon rank-sum test for independent data to test for differences in among-individual and within-individual $\mathrm{CV}$ of flower length and width and leaf length between zygomorphic and actinomorphic species. All analyses were done using the statistical software $\mathrm{R}$ (version 2.5.0; R Development Core Team 2007).

\section{RESULTS AND DISCUSSION}

Overall, the species in our study had a higher among-individual variation in leaf length than in flower length (Wilcoxon test statistic $V=0, P<0.001)$ and in flower width $(V=0, P<$ 0.001 ; Fig. 1, Table 1). This result is not very surprising because it confirms the general observation that the size of floral structures is less variable than the size of vegetative structures (Berg 1960; Bradshaw 1965). However, with the exception of a study by Armbruster et al. (1999), which showed that floral traits were less variable than vegetative traits in nine neotropical plant species, we are not aware of any other studies that specifically tested this hypothesis. Ushimaru et al. (2007) report data on variation in leaf length and flower size for 27 species, 

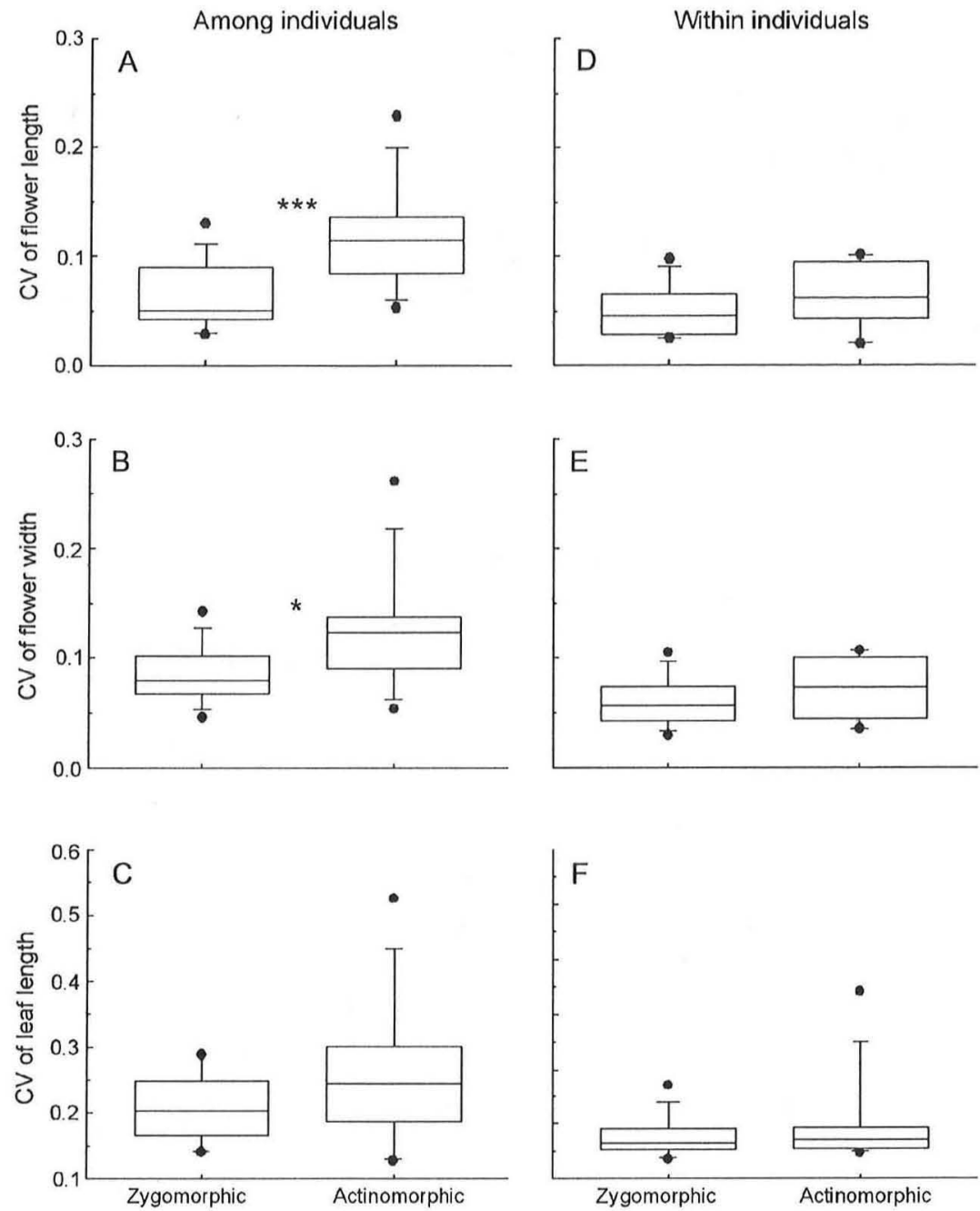

Figure 1: Coefficients of variation of (A, D) flower length, (B, E) flower width and (C, F) leaf length among individuals (A, B, C) and within individuals (D, E, F) of zygomorphic and actinomorphic species. The boundaries of the box around the median indicate the 75 th and 25 th percentiles. The whiskers indicate the 90 th and 10 th percentiles, and the dots indicate outliers. ${ }^{* * *} P<0.001 ; * P<0.05$.

and although they did not statistically compare the two measures, leaves were c. two times more variable than flowers. Together with our results this suggests that the size of flowers is more canalized than the size of vegetative structures. Another explanation for the relatively constant size of flowers is that they have in contrast to vegetative parts a relatively closed organization with certain primary morphological surfaces becoming enclosed during the early stages of their development (Endress 1990; Schmid 1992). Such a closed development, which is a general feature of animals, allows for less phenotypic plasticity and could actually be a consequence of canalized selection.

Zygomorphic species had significantly lower among-individual variation in flower length (Wilcoxon test statistic $U=27, P<$ $0.001)$ and flower width $(U=44, P=0.013)$ than actinomorphic species (Fig. 1A, B, Table 1). This suggests that stabilizing selection on flowers by pollinators has been stronger in zygomorphic species than in actinomorphic species. Alternatively, it could be that zygomorphic species are less variable overall than actinomorphic species for reasons other than stabilizing selection by pollinators. This is, however, unlikely because both groups of species did not differ in their among-individual variation of leaf length (Fig. 1C, Table $1 ; U=67, P=0.170$ ). Furthermore, among-individual variation in flower size could be larger for species that have both hermaphroditic and female or male flowers (i.e. species that are gynodioecious or androdioecious). However, if we restrict our analysis to species that are strictly hermaphroditic, the results and levels of significance remain qualitatively the same (data not shown). Our results for species in Europe and similar results for species in North America (Wolfe and Krstolic 1999) and Asia (Ushimaru et al. 
2007) indicate that flowers of zygomorphic species have globally undergone stronger pollinator-mediated stabilizing selection than actinomorphic species.

Among-individual variance of flower and leaf sizes was significantly larger than the within-individual variance of these traits (Fig. 1; flower length: $F_{490,378}=10.30, P<0.001$; flower width: $F_{490.378}=13.50, P<0.001$; leaf length: $F_{490.509}=9.04$, $P<0.001$ ), but there was still considerable variation within individuals (Fig. 1D-F). Although within-individual variation of flower length and width of zygomorphic species tended to be lower than the ones of actinomorphic species (Fig. 1D-F), none of the differences were significant (flower length: $U=$ 46, $P=0.115$; flower width: $U=52, P=0.216$; leaf length: $U=86, P=0.618)$. This indicates that although stabilizing selection, most likely mediated by pollinators, may have reduced among-individual variation in flower size more strongly for zygomorphic compared to actinomorphic species, this has not been the case for within-individual variation.

As for all between-species comparative studies, a potential limitation of our study is that the species are not independent data points due to shared evolutionary history of closely related species. One way to avoid this problem, which is now frequently applied, is the use of phylogenetically independent contrasts (Felsenstein 1985). Such contrasts can, however, be overly conservative because similarities among close relatives might in fact represent the adaptive outcome of stabilizing selection rather than phylogenetic constraint (Carvalho et al. 2006; Westoby et al. 1995).

The type of floral symmetry is highly conserved within families and particularly within genera (Neal et al. 1998). As a consequence, the number of possible phylogenetically independent contrasts between actinomorphic and zygomorphic species are low and mainly restricted to higher taxonomic levels such as subclasses (see Wolfe and Krstolic 1999). In our data set, only three phylogenetically independent contrasts are possible, using the phylogenetic code of the BiolFlor database (Klotz et al. 2002), and as a consequence there is not enough statistical power for an analysis based on phylogenetically independent contrasts. Although for the two species of the family Boraginaceae, the among-individual CV in flower length was slightly higher for the zygomorphic Echium vulgare than for the actinomorphic Myosotis sylvatica, for both the remaining seven species of the subclass Asteridae and for the 10 species of the subclass Rosidae, the among-individual CV in flower length was considerably lower for the zygomorphic than for the actinomorphic species (Table 1). The study of Wolfe and Krstolic (1999), which included six phylogenetic independent contrasts among their 31 study species, revealed no phylogenetic constraints on variation in flower size. Overall, this suggests that comparisons between actinomorphic and zygomorphic species are likely to be robust with respect to phylogeny.

\section{CONCLUSION AND OUTLOOK}

This study provides support for the notion that flowers are less variable than vegetative structures. Moreover, it provides sup- port for the PMSS hypothesis of Wolfe and Krstolic (1999) who predicted that variation in flower size should be smaller in zygomorphic species compared to actinomorphic species because the more specialized pollination systems of zygomorphic species require a more accurate physical fit between flower and pollinator. Therefore, we conclude that the relative uniformity of flowers compared to vegetative structures within species, as already observed in traditional plant systematics, is a consequence of the requirement for effective pollination.

Future studies on this topic should address whether zygomorphic species indeed have more specialized pollination systems (see Fenster et al. 2004) and higher effective pollination rates than actinomorphic species. Moreover, instead of indirect measures of stabilizing selection, selection gradient analysis (Lande and Arnold 1983) should be used to directly assess differences in stabilizing selection on flower size between actinomorphic and zygomorphic species.

\section{Acknowledgements}

We thank Patrick Kuss and Andreas Gygax for assistance and Melanie Glaettli, Steve Johnson, Bernhard Schmid and two anonymous reviewers for helpful comments of an earlier version of this manuscript.

\section{References}

Armbruster WS, Di Stilio VS, Tuxill JD, et al. (1999) Covariance and decoupling of floral and vegetative traits in nine Neotropical plants: a re-evaluation of Berg's correlation-pleiades concept. Am J Bot 86:39-55.

Berg RL (1960) The ecological significance of correlation pleiades. Evolution 14:171-80.

Bradshaw AD (1965) Evolutionary significance of phenotypic plasticity in plants. Adv Genet 13:115-56.

Carvalho P, Diniz-Filho JAF, Bini LM (2006) Factors influencing changes in trait correlations across species after using phylogenetic independent contrasts. Evol Ecol 20:591-602.

Endress PK (1990) Patterns of floral construction in ontogeny and phylogeny. Biol J Linn Soc 39:153-75.

Felsenstein J (1985) Phylogenies and the comparative method. Am Nat 125:1-15.

Fenster CB (1991) Selection on floral morphology by hummingbirds. Biotropica 23:98-101.

Fenster CB, Armbruster WS, Wilson P, et al. (2004) Pollination syndromes and floral specialization. Annu Rev Ecol Evol Syst 35: 375-403.

Grant V (1949) Pollination systems as isolation mechanisms in angiosperms. Evolution 3:82-97.

Klotz S, Kühn I, Durka W (2002) BIOLFLOR-eine Datenbank zu biologisch-ökologischen Merkmalen der Gefässpflanzen in Deutschland. In: Schriftenreihe für Vegetationskunde, 38. Bundesamt für Naturschutz: Bonn, Germany.

Lande R, Arnold SJ (1983) The measurement of selection on correlated characters. Evolution 37:1210-26. 
Midgley JJ, Johnson SD (1998) Some pollinators do not prefer symmetrically marked or shaped daisy (Asteraceae) flowers. Evol Ecol 12:123-6.

Møller AP, Eriksson M (1994) Patterns of fluctuating asymmetry in flowers: implications for sexual selection in plants. $J$ Evol Biol 7:97-113.

Neal PR, Dafni A, Giurfa M (1998) Floral symmetry and its role in plant-pollinator systems: terminology, distribution, and hypotheses. Annu Rev Ecol Syst 29:345-73.

Nilsson LA (1988) The evolution of flowers with deep corolla tubes. Nature 334:147-9.

R Development Core Team R: A Language and Environment for Statistical Computing. Vienna, Austria: R Foundation for Statistical Computing.

Sargent RD (2004) Floral symmetry affects speciation rates in angiosperms. P Roy Soc Lond B 271:603-8.
Schmid B (1992) Phenotypic variation in plants. Evol Trends Plants 6:45-60.

Stebbins GL (1951) Natural selection and differentiation of angiosperm families. Evolution 5:299-324.

Stebbins GL (1970) Adaptive radiation of reproductive characteristics in angiosperms. I. Pollination mechanisms. Annu Rev Ecol Syst 1:307-26.

Ushimaru A, Kikuchi S, Yonekura R, et al. (2007) The influence of floral symmetry and pollination systems on flower size variation. Nord $J$ Bot 24:593-8.

Westoby M, Leishman MR, Lord JM (1995) On misinterpreting the "phylogenetic correction". J Ecol 83:531-4.

Wolfe LM, Krstolic JL (1999) Floral symmetry and its influence on variance in flower size. Am Nat 154:484-8. 